\title{
BMJ Open Attitudes of pharmacy students towards patient safety: a cross-sectional study from six developing countries
}

\author{
Abdallah Y Naser (D) , ${ }^{1}$ Zahra Khalil Alsairafi, ${ }^{2}$ Ahmed Awaisu, ${ }^{3}$ Hassan Alwafi (D) ${ }^{4}$ \\ Oriana Awwad, ${ }^{5}$ Eman Zmaily Dahmash, ${ }^{1}$ Salman Hussain (1) , ${ }^{6}$ Hamad S Alyami, ${ }^{7}$ \\ Alaa Alsharif, ${ }^{8,9}$ Avinash Kumar Singh, ${ }^{6}$ Fatima B Jeragh-Alhaddad, ${ }^{2}$ \\ Angga Prawira Kautsar, ${ }^{10}$ Amal Khaleel AbuAlhommos ${ }^{11}$
}

To cite: Naser AY, Alsairafi ZK, Awaisu A, et al. Attitudes of pharmacy students towards patient safety: a crosssectional study from six developing countries. BMJ Open 2020;10:e039459. doi:10.1136/ bmjopen-2020-039459

- Prepublication history and additional materials for this paper is available online. To view these files, please visit the journal online (http://dx.doi org/10.1136/bmjopen-2020039459).

Received 15 April 2020 Revised 17 October 2020 Accepted 13 November 2020

Check for updates

(c) Author(s) (or their employer(s)) 2020. Re-use permitted under CC BY-NC. No commercial re-use. See rights and permissions. Published by BMJ.

For numbered affiliations see end of article.

Correspondence to Dr Abdallah Y Naser; abdallah.naser@iu.edu.jo

\section{ABSTRACT}

Objective To evaluate the attitudes of undergraduate pharmacy students towards patient safety in six developing countries.

Design A cross-sectional study.

Setting Participants were enrolled from the participating universities in six countries.

Participants Undergraduate pharmacy students from the participating universities in six developing countries (Jordan, Saudi Arabia, Kuwait, Qatar, India and Indonesia) were invited to participate in the study between 0ctober 2018 and September 2019.

Primary outcome Attitudes towards patient safety was measured using 14-item questionnaire that contained five subscales: being quality-improvement focused, internalising errors regardless of harm, value of contextual learning, acceptability of questioning more senior healthcare professionals' behaviour and attitude towards open disclosure. Multiple-linear regression analysis was used to identify predictors of positive attitudes towards patient safety.

Results A total of 2595 students participated in this study (1044 from Jordan, 514 from Saudi Arabia, 134 from Kuwait, 61 from Qatar, 416 from India and 429 from Indonesia). Overall, the pharmacy students reported a positive attitude towards patient safety with a mean score of $37.4(S D=7.0)$ out of $56(66.8 \%)$. The 'being quality-improvement focused' subscale had the highest score, $75.6 \%$. The subscale with the lowest score was 'internalising errors regardless of harm', 49.2\%. Female students had significantly better attitudes towards patient safety scores compared with male students $(p=0.001)$. Being at a higher level of study and involvement in or witnessing harm to patients while practising were important predictors of negative attitudes towards patient safety $(p<0.001)$.

Conclusion Patient safety content should be covered comprehensively in pharmacy curricula and reinforced in each year of study. This should be more focused on students in their final year of study and who have started their training. This will ensure that the next generation of pharmacists are equipped with the requisite knowledge, core competencies and attitudes to ensure optimal patient safety when they practice.
Strengths and limitations of this study

- This is the first study comprising participants from multiple countries to investigate the attitudes of undergraduate pharmacy students towards patient safety in the Middle East region.

- We were not able to estimate the response rate for our study, which might have led to non-response bias.

- The study sample was mainly dominated by students from two countries (Jordan and Saudi Arabia), while there was a small number of participants from Qatar and Kuwait.

\section{INTRODUCTION}

Patient safety is one of the main concerns of healthcare systems during the provision of healthcare services and is increasingly being used as a measure of healthcare quality. WHO has stressed the importance of reducing healthcare errors and establishing action plans to reduce patient harm and increase patient safety. ${ }^{1}$ Medical errors are associated with high probability of patients harm and high mortality rate which raised the need for strategies that are evidence based to enhance patient safety. ${ }^{2}$ Research results revealed that around $10.0 \%$ of patients admitted to hospital within developed countries have a chance of being harmed, and up to $18.0 \%$ of hospital admissions experienced adverse events. Besides, there is a growing concern pertinent to the level of harm among patients in developing countries that could be attributed to the lack of accountability. ${ }^{3-5}$

One of the best strategies to promote safer attitudes towards patient safety is education. ${ }^{67}$ Patient safety education for undergraduate healthcare students has been considered a crucial element in minimising patient harm and developing a positive patient safety culture. ${ }^{8}$ Several key international 
organisations have made recommendations to reshape healthcare professional education curricula to guarantee that they foster students' attitudes towards patient safety through enhancing their knowledge, skills and attitudes. ${ }^{9-14}$ In recent years, pharmacy degree programmes have included content related to patient safety through curriculum guides, ${ }^{5}$ including the WHO's Patient Safety Curriculum Guide for Medical Schools ${ }^{15}$ and their Multiprofessional Patient Safety Curriculum Guide. ${ }^{16-19}$ Pharmacy students, in developing countries, gain some practical experience in healthcare settings at an earlier stage of their studies, either through experiential education placements or simulation-based programmes. ${ }^{20}$ However, unlike other healthcare professions, pharmacists' training is not well structured and does not mandate close monitoring of students during their training by preceptors. Although patient-centred care and patient safety might have been embedded through the curriculum, it has been mostly informal and theoretical. ${ }^{4521}$

Unfortunately, there is no recent studies that described the curricula in the Middle Eastern countries, However, a study in 2008, in Jordan reported that curricula at various pharmacy schools covers only $20 \%$ of allocated credit hours in pharmaceutical care which covers elements of patient safety. A study with sample of government and private universities in Jordan concluded that none of the evaluated universities had adopted a structured patient-oriented training for students. ${ }^{22}$ In Qatar, the pharmacy practice focuses mainly on medication dispensing, and patient care that includes patient safety is still in its infancy. ${ }^{23}$ Similar situations are present in Kuwait and Saudi Arabia where pharmaceutical care is only a focused in Pharm D programme not the BSc Pharmacy programme. ${ }^{24}$ The situation in India is not widely different, there is no standard curriculum and it varies across universities. Most pharmacy school's education is away from practice sites and compulsory training is not required. ${ }^{25}$ In Indonesia, recent study in 2020 revealed that the provision of the pharmaceutical care that covers patient cantered care and safety by community pharmacists in Malaysia is minimal. ${ }^{26}$

In developing countries, there are cultural concerns, where pharmacy students are intimidated by other healthcare professionals particularly, physicians, when they are in the clinical practice setting which will hamper patient safety. The 'hierarchical difference in medical knowledge' will make young pharmacists' reluctance to question decisions made by physicians. ${ }^{5} 27$ Therefore, improving patient safety in developing countries requires changing attitude particularly in shifting the blame culture in healthcare settings.

Efforts to foster patient safety in developing countries must be augmented and education systems during undergraduate level must provide knowledge to improve patient safety. ${ }^{27}$

Despite the increasing effort to enhance patient safety through improving healthcare professional curricula, this improvement is considered challenging, and progress is very slow. ${ }^{5} 1213$ 28-33 Developing positive attitudes among university students is important as it is positively related to their achievement. ${ }^{34}$ The accomplishment of educational goals related to delivering safe and quality healthcare services requires students to have positive attitudes towards patient safety. ${ }^{34}{ }^{35}$ Since attitude can substantially impact an individual's behaviour and practice, ${ }^{36}$ it is crucial that pharmacy students' attitudes towards patient safety are understood and evaluated particularly in developing countries.

Previous studies have explored the attitudes and values of healthcare students towards patient safety in different countries, using different instruments. ${ }^{18} 1937-44$ The most widely used validated tool is the patient safety/medical fallibility survey, which was originally developed by Madigosky et al for use among medical students. ${ }^{37}$ This tool was validated to assess the patient safety attitudes of pharmacy students by Walpola et al. ${ }^{45}$ However, there are a limited number of studies that have focused on attitudes of undergraduate pharmacy students towards patient safety, especially in developing countries. Therefore, the aim of this study was to evaluate the attitudes of undergraduate pharmacy students towards patient safety in six developing countries.

\section{METHODS}

\section{Study design}

A quantitative cross-sectional survey using a selfadministered questionnaire was conducted to explore patient safety attitudes and values among pharmacy students in six developing countries (Jordan, Saudi Arabia, Kuwait, Qatar, India and Indonesia). To achieve the study aim, a self-administered questionnaire approach was adopted. This approach has the advantage of being easily administered to a large number of participants within a short time period, eliminating interviewer bias. ${ }^{46}$ In addition, this technique can easily explain students' behaviour. $^{47}$

\section{Sample size}

Based on the original study conducted by Walpola $e t a t^{45}$ a sample size of 200 students from each country was considered adequately representative. The original study estimated the appropriate sample size based on Boomsma's method of estimating a minimum sample size to conduct a confirmatory factor analysis based on the number of items to number of factors ratio of the model. ${ }^{48}$

\section{Sampling strategy}

The study population included undergraduate pharmacy students across all professional years of study. A convenience sampling technique was used to recruit eligible participants as it was not feasible to determine a sampling frame in each of the six countries. This sampling technique is a type of non-probability sampling method, in which participants from the target population who met the inclusion criteria of the study were easily accessible 
due to geographical proximity, availability at a given time, or were willing to take part in the study. ${ }^{49}$ Student recruitment was conducted by researchers (AYN and OA) in Jordan, (AAl) in Saudi Arabia, (ZKA) in Kuwait, (AAw) in Qatar, (SH) in India and (APK) in Indonesia. The questionnaire was administered either as a hard copy or electronically to eligible participants in a consistent manner to reduce the risk of assessment bias. All the undergraduate pharmacy students in the participating universities were approached and invited to take part in the study. For students who agreed to participate, the questionnaire was administered either as a hard copy or electronically after the study aim and objectives had been explained.

\section{Survey instrument}

A previously validated questionnaire ${ }^{45}$ was used in this study to explore the attitudes of undergraduate pharmacy students towards patient safety. This questionnaire was originally developed and validated by Walpola et $a l$, who validated an adaptation of Madigosky et als questionnaire (the Patient Safety/Medical Fallibility Curriculum Survey), ${ }^{37}$ to evaluate attitudes and values of pharmacy students towards patient safety. Walpola $e t$ $a l$ s 14-item questionnaire comprised five subscales: (1) quality-improvement focused (four questions), (2) internalising errors regardless of harm (three questions), (3) value of contextual learning (three questions), (4) acceptability of questioning more senior healthcare professionals' behaviour (two questions) and (5) attitude towards open disclosure (two questions). The study questionnaire asked undergraduate pharmacy students about the degree of applicability of each item to them using a 5-point Likert scale. Response options ranged from 0 to 4 , where 0 meant 'strongly disagree' and 4 meant 'strongly agree'. Three items (items numbered 5, 6 and 7) were negatively worded and, thus, were reversely scored during the analysis, where 0 meant 'strongly agree' and 4 meant 'strongly disagree'. The total possible score for the questionnaire ranged between 0 and 56 and could be interpreted based on the midpoint of the highest possible score of the scale (equal to 28): the higher the score, the better the attitude towards patient safety. Besides, the following data were collected: participant's gender, year of study, prior practical experience in healthcare settings-if applicable, and involvement in an incident that resulted in harm or potential harm as a result of receiving healthcare.

The use of a pre-existing questionnaire has the advantage of using a validated and tested instrument, which increases the reliability of measurement. ${ }^{50}$ In addition, the use of an existing questionnaire allows for comparison with different populations. ${ }^{51}$ The mean score $\pm \mathrm{SD}$ for each item was calculated based on the student responses using the 5-point Likert scale, which ranged between 0 and 4 . In addition, the total mean score for each subscale was calculated to allow comparison between different subscales.

\section{Validity and reliability of the survey instrument}

Walpola's questionnaire was examined for its psychometric properties in 446 students. ${ }^{45}$ The face and content validity of the questionnaire were tested. In addition, exploratory factor analysis was conducted to test the construct validity and the internal consistency of the questionnaire was examined. In addition, the original investigators conducted focus groups among three populations: initially among five pharmacy academics, five practising pharmacists and seven pharmacy student representatives to assess the face validity of the survey instrument. Besides this, we examined Cronbach's alpha measures for the five factors in the questionnaire, which ranged between 0.56 and 0.78. The overall Cronbach's alpha measure was 0.72 (Cronbach's alpha value for each subscale is included in online supplemental file). This identified the questionnaire as having acceptable stability.

\section{Pretesting of the questionnaire}

A pilot study using the original questionnaire was conducted on 45 pharmacy students (from different Arab nationalities) in Jordan, who met the inclusion criteria for the study. Students were asked about the clarity and comprehensibility of the questionnaire, and if any of the questions were difficult to understand. Students confirmed that the questionnaire was considered easy to understand and to complete.

\section{Data collection procedure}

In Jordan, we used hard copies of the questionnaire, and the recruitment of participants was conducted in two universities (one private and one government). An electronic version of the questionnaire was used for the students recruited in the other countries. In Saudi Arabia, the survey was distributed in three government universities. In Indonesia, student recruitment was conducted in two government universities, while in India it was conducted in five universities. In Kuwait and Qatar, the study was conducted in one government university in each country, these being the only available ones that offer an undergraduate pharmacy degree programme.

\section{Patient and public involvement}

It was not appropriate or possible to involve patients or the public in the design, or conduct, or reporting, or dissemination plans of our research.

\section{Statistical analysis}

Data were analysed using SPSS software, V.25 (IBM). Continuous variables were reported as mean $( \pm \mathrm{SD})$, while categorical variables were reported as frequencies and percentages. The Kolmogorov-Smirnov and Shapiro Wilk tests were used to check the normality of the data. Students' scores were interpreted as a continuous scale based on the scale midpoint, where scores above the midpoint represented more positive attitudes towards patient safety for that factor. The one-way analysis of variance test and Pearson's correlation coefficient were used to compare the mean scores between 
different demographic groups and to analyse the correlation between continuous independent variables and students' scores, respectively. Tukey's honestly significant difference (HSD) post hoc test was conducted to identify the source of significant variation within each group. Additionally, significant predictors of positive attitudes towards patients' safety were determined using multiple linear regression analysis. A 95\% CI $(\mathrm{p}<0.05)$ was applied to represent the statistical significance of the results, and the level of significance was predetermined as $5 \%$.

\section{RESULTS}

\section{Students' demographic characteristics}

A total of 2595 undergraduate pharmacy students participated in the study (Jordan=1044, Saudi Arabia=514, Indonesia $=429$, India $=416$, Kuwait $=134$ and Qatar $=61$ ). About $67.0 \%(n=1752)$ of the students were female. The majority of the respondents were recruited from Jordan $(\mathrm{n}=1044 ; 39.9 \%)$, followed by Saudi Arabia ( $\mathrm{n}=514$; $19.7 \%$ ). An approximately similar percentage of participants were recruited from Indonesia $(n=429 ; 16.5 \%)$ and India $(n=416 ; 16.0 \%)$. The lowest percentages of participants came from Kuwait and Qatar, with only 5.2\% $(\mathrm{n}=134)$ and $2.4 \%(\mathrm{n}=61)$ being recruited from these two countries, respectively. This was expected due to the small population size, and thus, the small number of pharmacy students (Kuwait and Qatar only have one faculty of pharmacy each). The majority of the students were in their 3rd and 4th year of study with $21.0 \%(\mathrm{n}=546)$ and $26.2 \%$ $(\mathrm{n}=679)$, respectively. Only $38.2 \% \quad(\mathrm{n}=990)$ of the participants reported that they had had prior or were undergoing current practical experience in a practice setting, with only $27.4 \% \quad(n=712)$ of the participants have been involved in or have witnessed harm to patients while practising. Table 1 summarises the demographic characteristics of the study participants from each country.

\section{Pharmacy students' attitude towards patient safety}

The mean score of the participants for the total scale was $37.4(\mathrm{SD}=7.0)$ out of 56 (the highest possible score), $66.8 \%$. The first subscale measured students' attitude in terms of 'being quality-improvement focused'. The participants' score was the highest for this scale, $75.6 \%$. The lowest score was for the 'internalising errors regardless of harm' subscale, $49.2 \%$.

The highest mean score for the total scale was for India (40.6 $(\mathrm{SD}=5.5), 72.5 \%)$. India had the highest subscale score for the subscale 'value of contextual learning' (9.5 $(\mathrm{SD}=1.7), 79.2 \%)$. Qatar had the highest subscale score for two subscales which are 'being quality improvement focused' (13.9 (SD=1.6), 86.9\%) and 'acceptability of questioning more senior healthcare professionals' behaviour' (6.5 ( $\mathrm{SD}=1.3), 81.3 \%)$. The score of the subscale 'attitude towards open disclosure' was similar across students from Indonesia, India, and Qatar with a mean score that range between $6.0(\mathrm{SD}=1.4)$ and $6.0(\mathrm{SD}=1.7), 75.0 \%$. Jordan had the highest subscale score for the subscale 'internalising errors regardless of harm' (8.1 ( $\mathrm{SD}=2.6), 67.5 \%)$. Table 2 summarises these findings.

\section{Effect of students' characteristics on their attitude towards patients' safety}

Table 3 presents the effect of the students' demographics on their attitude towards patient safety scores. Students' scores significantly differed by country, gender, year of study, having prior experience in healthcare and being involved in or having witnessed harm to patients while practising $(\mathrm{p}<0.01)$. Tukey's HSD post hoc test confirmed that all countries contributed to the significant difference in the mean score except Indonesia, and that Saudi Arabia, Kuwait and India had the most significant contributions in this variation. Regarding the year of study variable, the Tukey HSD test confirmed that all years of study contributed to the significant variation between groups.

\begin{tabular}{|c|c|c|c|c|c|c|c|}
\hline Demographics & $\begin{array}{l}\text { Overall } \\
(n=2595)\end{array}$ & $\begin{array}{l}\text { Jordan } \\
(n=1044)\end{array}$ & $\begin{array}{l}\text { Saudi Arabia } \\
(n=514)\end{array}$ & $\begin{array}{l}\text { Indonesia } \\
(n=429)\end{array}$ & India $(n=416)$ & $\begin{array}{l}\text { Kuwait } \\
(n=134)\end{array}$ & $\begin{array}{l}\text { Qatar } \\
(n=61)\end{array}$ \\
\hline Female & $1752(67.5)$ & $741(71.0)$ & $323(62.8)$ & $388(90.4)$ & $124(29.8)$ & $115(85.8)$ & $61(100)$ \\
\hline \multicolumn{8}{|c|}{ Year of study no (\%) } \\
\hline Third year & $546(21.0)$ & 243 (23.3) & $110(21.4)$ & $60(14.0)$ & $57(13.7)$ & $67(50.0)$ & $9(14.8)$ \\
\hline Fourth year & 679 (26.2) & $319(30.6)$ & $232(45.1)$ & $29(6.8)$ & $64(15.4)$ & $22(16.4)$ & $13(21.3)$ \\
\hline Fifth year & $452(17.4)$ & $260(24.9)$ & $142(27.6)$ & $7(1.6)$ & $22(5.3)$ & $13(9.7)$ & $11(18.0)$ \\
\hline \multicolumn{8}{|c|}{ Prior healthcare experience no (\%) } \\
\hline
\end{tabular}




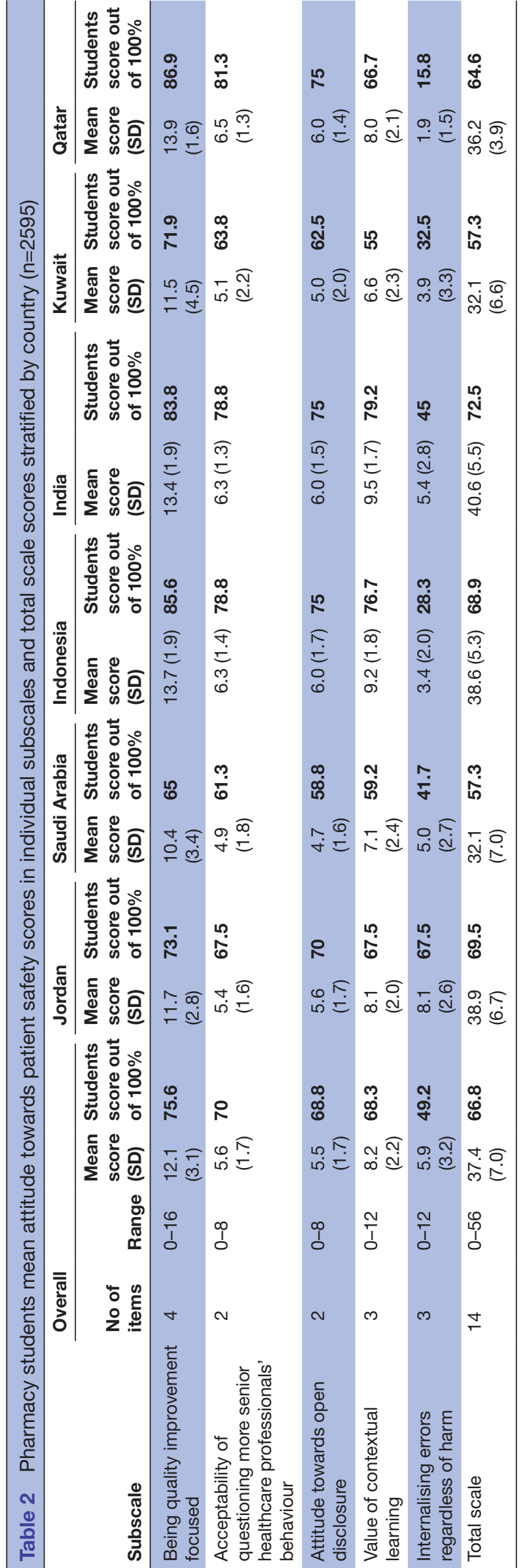

\begin{tabular}{|c|c|c|c|}
\hline \multirow[b]{2}{*}{ Variable } & \multicolumn{3}{|c|}{ Patients' safety scores } \\
\hline & Mean & SD & $P$ value \\
\hline \multicolumn{4}{|l|}{ Country } \\
\hline Jordan & 38.9 & 6.7 & $0.000^{\star \star \star}$ \\
\hline Saudi Arabia & 32.1 & 7 & \\
\hline Indonesia & 38.6 & 5.3 & \\
\hline India & 40.6 & 5.5 & \\
\hline Kuwait & 32.1 & 6.6 & \\
\hline Qatar & 36.2 & 3.9 & \\
\hline \multicolumn{4}{|l|}{ Gender } \\
\hline Male & 36.6 & 7.8 & $0.000^{\star \star \star}$ \\
\hline Female & 37.7 & 6.6 & \\
\hline \multicolumn{4}{|l|}{ Year of study } \\
\hline First year & 39.3 & 6.1 & $0.000^{\star \star \star}$ \\
\hline Second year & 37.8 & 6.8 & \\
\hline Third year & 37 & 6.9 & \\
\hline Fourth year & 36.4 & 7.7 & \\
\hline Fifth year & 36.8 & 7.1 & \\
\hline \multicolumn{4}{|c|}{ Prior healthcare experience } \\
\hline Yes & 36.8 & 7.4 & $0.001^{* *}$ \\
\hline No & 37.7 & 6.8 & \\
\hline \multicolumn{4}{|c|}{$\begin{array}{l}\text { Ever been involved in or witnessed harm to patients while } \\
\text { practising }\end{array}$} \\
\hline Yes & 36.2 & 7.8 & $0.001^{* *}$ \\
\hline No & 37.8 & 6.7 & \\
\hline
\end{tabular}

${ }^{*} \mathrm{P}<0.01,{ }^{\star \star \star} \mathrm{p}<0.001$

Simple linear regression analysis showed that all demographic variables were significantly associated with a better attitude towards patients' safety score $(p<0.01)$. Multiple linear regression analysis showed that female students had a better attitude towards patients' safety score $(\mathrm{p}=0.001)$. In addition, it showed that higher-level students and being involved in or having witnessed harm to patients while practising were associated with a slightly lower score $(\mathrm{p}=0.000)$, table 4 .

\section{DISCUSSION}

The current study has identified the attitudes of undergraduate pharmacy students towards patients' safety. The sample was collected from different universities in different countries, across all years of study for the pharmacy programme, and using a previously validated tool. The data was collected from a large sample compared with previous similar studies. For example, Carruthers et al conducted a questionnaire-based study on 364 undergraduate medical students and 66 tutors from one medical school in the UK, ${ }^{6}$ while Tegegn et al conducted their study with a population of 83 students from a single 
Table 4 Multiple linear regression analysis predicting students' attitude towards patients' safety

\section{Model†i}

\begin{tabular}{|c|c|c|c|c|}
\hline Variable & B & SE & B & $95 \% \mathrm{Cl}$ \\
\hline \multicolumn{5}{|c|}{ Demographic data } \\
\hline Males & \multicolumn{4}{|c|}{ Reference category } \\
\hline Females & 0.96 & 0.29 & $0.06^{\star \star}$ & (0.38 to 1.53$)$ \\
\hline \multicolumn{5}{|c|}{ Year of study } \\
\hline First year & \multicolumn{4}{|c|}{ Reference category } \\
\hline Second year & -1.5 & 0.46 & $-0.08^{\star *}$ & $(-2.35$ to -0.54$)$ \\
\hline Third year & -2.2 & 0.43 & $-0.13^{\star \star \star}$ & $(-3.04$ to -1.36$)$ \\
\hline Fourth year & -2.8 & 0.42 & $-0.17^{\star \star \star}$ & $(-3.60$ to -1.93$)$ \\
\hline Fifth year & -2.4 & 0.42 & $-0.13^{\star \star \star}$ & $(-3.34$ to -1.48$)$ \\
\hline
\end{tabular}

Having prior experience in healthcare

\begin{tabular}{lllll} 
No & \multicolumn{4}{l}{ Reference category } \\
Yes & 0.21 & 0.33 & 0.01 & (-0.43 to 0.85)
\end{tabular}

Being involved in or witnessed harm to patients while practising

\begin{tabular}{|c|c|c|}
\hline No & \multicolumn{2}{|c|}{ Reference category } \\
\hline Yes & -1.2 & $-0.07^{\star \star \star} \quad(-1.81$ to -0.53$)$ \\
\hline \multicolumn{3}{|l|}{ Constant } \\
\hline Adjusted $\mathrm{R}^{2}$ & & 0.03 \\
\hline $\mathrm{P}$ value & & 0 \\
\hline
\end{tabular}

B: the average change in the depenedent variable associated with a 1 unit change in the independent variable, statisitcally controlling for the other independent variables; SE: it is the SD of its sampling distribution or an estimate of that SD; B: a statistical measure that compares the strength of the effect of each individual independent variable to the dependent variable.

${ }^{* \star *} \mathrm{p}<0.01,{ }^{* \star *} \mathrm{p}<0.001$.

†Includes gender, year of study, having prior experience in healthcare, and being involved in or witnessed harm to patients while practising.

university in Ethiopia. ${ }^{52}$ Also, there were previous surveys conducted by Tegegn et $a \tilde{l}^{2}$ and Carruthers et $a l^{6}$ which did not obtain data on the nationality of the participants. This limited our ability to make direct comparisons between different nationalities settings. The results highlighted that, generally, a positive attitude towards patient safety was an important issue among pharmacy undergraduate students. There was a small but significant difference in attitudes between male and female pharmacy students. These results are comparable with those of another previous study ${ }^{52}$ where $86.7 \%$ of female respondents had an overall positive attitude to patient safety compared with $83 \%$ of their male counterparts. Neither the previous nor the current study was able to explain this difference, and a further study of attitudes of male and female students towards patient safety is required to elucidate whether this is a real gender-influenced trait. Female students could be more emotional and sensitive to patients' health outcomes, therefore, this would make them more proactive and have stronger drive to act towards safer practices.

Comparison in terms of patient safety elements revealed variations among countries. The first subscale focused on 'students being quality improvement focused' with results highlighting the superiority of Qatar, Indonesia and India over the other countries. Such difference could be attributed to students in these countries receiving education more pertinent to patient safety and the science behind it that could cover medication errors, drug adverse events and their effect in optimising patient outcomes. Although there are no recent research indicating that in these countries patient safety is fundamental in curricula, results reflect presence of such teaching modules, where studies reported that integrating patient safety in curricula will improve student knowledge. ${ }^{53}$ Similar results were obtained in the second and third subscales which focused on addressing 'the acceptability of questioning more senior healthcare professionals' behaviour' and 'attitude towards open disclosure' which apparently put an emphasis on something that is a consequence of what has been taught. In these subscales the scores were lower than the first subscale and this could be expected, where students attitude will enable them to develop a culture of understanding and preventing errors from occurring, ${ }^{45}$ which apparently requires practice and elements that are beyond knowledge and hence the lower score of these two subscales were obtained when compared with the first one.

As for the fourth subscale 'value of contextual learning', Indonesia and India scored the highest. Here, the domain is assessing the students belief in the need to the delivery of patient safety interventions and teaching materials. ${ }^{45}$ Apparently, students who have good level of knowledge about patient safety will value the need to integrate that into curricula and healthcare setting and hence the results reflected that. The last subscale assessed' students' attitude pertinent to internalising errors regardless of harm', this subscale is related to the attitude of students in internalising the error rather than taking action and this section provides good indication whether students would manage risks and errors that could or not affect patients. Results showed that Jordan scored the highest among the seven countries while Qatar scored the lowest. Although Jordan did not score the highest among the countries in the first four subscales, it scored around the mean and none of the sections was below $67.0 \%$ indicating a positive attitude towards patient safety. This last subscale is critical in fostering a patient safety culture. As this attitude is related to the presence of transparency and willingness to reporting errors. Despite variations and slightly lower scores, Jordan scores were above average and their score in the final subsection rated the highest among the seven countries. Future research is required to assess the pharmacy curricula in developing countries. Interestingly, students' attitude towards patient safety in Kuwait and Saudi Arabia, neighbouring countries with similar cultural values, reported the lowest among the seven 
countries. The average of scores for the two countries showed results that are shy above the $50 \%$ mark. It could be expected that in these two countries patient safety is still in its infancy phase.

In the current study, there were two factors which have been negatively correlated with attitudes towards patient safety; these are the 'year of study' and 'being involved in or having witnessed harm to patients while practising'. Similar findings were reported in a previous study and showed that students in their early years of study had higher scores (a better attitude towards patient safety) compared with others in their final years of training. ${ }^{54}$ This could have arisen among the students due to a lack of formal and well-structured teaching on patient safety that build up with years of study and have led to the reluctance to adopt patient safety practices. In addition, other literature reported that professional socialisation plays a big role in shifting students' and interns' attitudes, ${ }^{55}$ which could be another important influencing factor. These results are inconsistent with another study's results among pharmacy students in Ethiopia. ${ }^{52}$ Such a difference between the studies could be due to variations in the study settings, the recruited participants or, possibly, due to the greater emphasis allocated to teaching patient safety to students in specific countries over others. A follow-up study focusing on the change in attitudes towards the pharmacy teaching course is required. In addition, there is a need for the reinforcement towards patient safety throughout the pharmacy programme. This has also been recommended previously in studies about attitudes towards patient safety among medical students. ${ }^{66}$ In a previous study, medical students who had received education on patient safety attached greater importance to this topic and had more confidence in reporting incidences of poor patient safety. ${ }^{6}$ Also, it has been highlighted previously that there is a lack of patient safety education among a range of clinical disciplines, including medical, nursing and pharmacy students. ${ }^{57} 58$ Patient safety education has the potential to revolutionise the attitudes of pharmacists and pharmacists-in-training, which has broad implications for practice. ${ }^{57}$

In addition to the importance of educating patient safety at the university level, there is a need for constant reinforcement of messages regarding patient safety. In one study, it has been reported that some of the positive messages regarding improving patient care, which were taught to second-year medical students, had been forgotten after 1 year. ${ }^{37}$ Those students were also less likely to be open about the errors they had witnessed and less likely to believe that it was necessary to disclose errors that had not caused patient harm. Similarly, in the present study, it has been found that $49 \%$ of students agreed that errors should be internalised, regardless of harm to patients. Pharmacy students in Ethiopia shared the same belief in reporting self-errors, where only half of the students agreed, or strongly agreed, that pharmacists should report errors concerning a patient in situations where harm had occurred. ${ }^{52}$ A previous study in Pakistan that assessed the attitudes and perceptions of postgraduate students towards patient safety reported consistent findings: that students felt less confident in reporting any error other people had made in the work environment, no matter how serious the outcome had been for the patient. ${ }^{54}$ Many studies from different countries have reported that healthcare students have a common belief that medical errors are inevitable, and that even very experienced people make medical errors. ${ }^{54} 565960$ Reporting medical errors is important, and a failure to report such types of error indicates a lack of awareness of the risky consequences of such practice to the healthcare services provided to the patients. This finding has an implication for further research to understand the reasons for this behaviour; whether it is from a fear of reprisal from colleagues or patients or a lack of recognition of reporting as part of the duty of care to patients. However, incompatible results have been reported in North America, where the majority of students had positive attitudes towards reporting serious errors when they encountered them, but they had inadequate knowledge about the process of reporting them. ${ }^{61}$ Also, in that study, it can be seen that some students had conflicting attitudes towards reporting errors. They believed that reporting them would compromise interprofessional relationships, reduce the patients' confidence in the healthcare system and interrupt the workflow.

\section{Strengths and weaknesses}

The current study has many strengths. First, to the best of our knowledge, this study is the first large-scale study comprising participants from multiple nations (six countries), which suggests the evidence is robust and more generalisable. The data were collected from a large sample compared with previous similar studies from different countries. Second, the research used a validated questionnaire and a non-biased recruitment process, which provided reassurance of the quality of the study and the findings reported. ${ }^{45}$ However, there are some limitations. The study design itself, a cross-sectional survey design, limited our ability to identify causality between study variables. A further limitation of the current study was the small number of participants from some of the participating countries (Qatar; $n=61$, and Kuwait; $n=134$ ), and the dominance of the sample size by students from only two countries Jordan (39.9\%) and Saudi Arabia (19.7\%). However, due to the small population size in Qatar and Kuwait, and knowing that we recruited students from the only two available faculties of pharmacy in these two countries, we assume that these small numbers are sufficient to draw conclusions from. Future research should consider a wider range of countries during the recruitment phase to identify whether the findings can be expanded. Finally, we were not able to estimate the response rate for our study, which might lead to non-response bias, as we could not demonstrate how well the sample drawn from the population of interest. Therefore, the findings should be interpreted carefully. 


\section{Implications of findings to practice}

The findings of this study can help curricula developers to focus on patient safety teaching and make it an essential part of pharmacy curricula. Continuous educational sessions on patient safety and the reporting of errors in patient care will help in raising the students' knowledge and awareness of patient safety and medical errors. In addition, to ensure the quality of care and patient safety, it is important to provide clinical and senior supervision when students are given tasks related to patient safety at all levels of the pharmacy programme. Future studies to investigate the factors and attitudes of pharmacists and pharmacy students are warranted. Cultural and regional factors are important and must be taken into account when conducting future research. However, it is also important to mention that future research should also be conducted at the patient-level to study and explore patient safety from different perspectives.

In conclusion, the current study has revealed the positive attitudes of pharmacy students towards patient safety. There is currently limited number of research regarding the effect of pharmacy students' attitudes and the wider implications for practice specifically, the Middle East and other developing countries. Patient safety should be covered explicitly during the pharmacy students' education and reinforced at each year of study within the curriculum to ensure that the next generation of pharmacists is equipped with the knowledge and behaviours to ensure good patient safety. An additional focus should be placed on the area of patient safety to investigate further the key findings of the current study.

\section{Author affiliations}

${ }^{1}$ Department of Applied Pharmaceutical Sciences and Clinical Pharmacy, Isra University, Amman, Jordan

${ }^{2}$ Department of Pharmacy Practice, Faculty of Pharmacy, Kuwait University, Kuwait, Kuwait

${ }^{3}$ Department of Clinical Pharmacy and Practice, College of Pharmacy, QU Health, Qatar University, Doha, Qatar

${ }^{4}$ Department of Pharmacology and Toxicology, Umm Al-Qura University, Makkah, Saudi Arabia

${ }^{5}$ Department of Biopharmaceutics and Clinical Pharmacy, The University of Jordan, Amman, Jordan

${ }^{6}$ Department of Pharmaceutical Medicine (Division of Pharmacology), School of Pharmaceutical Education and Research, Jamia Hamdard, New Delhi, India ${ }^{7}$ Department of Pharmaceutics, College of Pharmacy, Najran University, Najran, Saudi Arabia

${ }^{8}$ Research Department of Practice and Policy, UCL School of Pharmacy, London, UK ${ }^{9}$ Department of Pharmacy Practice, College of Pharmacy, Princess Nourah bint Abdulrahman University, Riyadh, Saudi Arabia

${ }^{10}$ Faculty of Pharmacy, Universitas Padjadjaran, Bandung, Jawa Barat, Indonesia

${ }^{11}$ Pharmacy Practice Department, Clinical Pharmacy College, King Faisal University, Al-Hasa, Eastern, Saudi Arabia

\section{Twitter Angga Prawira Kautsar @kautsar_ap}

Acknowledgements This study was supported by Isra University (Amman, Jordan). We would like to thanks Saudi Ministry of Education for their support. Alaa Alsharif was funded by the Deanship of Scientific Research at Princess Nourah bint Abdulrahman University through the Fast-track Research Funding Program. In addition, the authors acknowledge Mohammad Alkharouf, Leena Abdullah and Asma Almashayekh for helping in collection of data in Jordan.
Contributors The authors who contributed to the work described in this paper are as follows: AYN contributed to the study design. AYN, ZKA, AAw, HA, SH, OA, AAl and APK conducted the study and collected data. AYN conducted to the data analysis. AYN, ZKA, HA, OA, AAw and EZD were involved in interpretation of data. AYN, ZKA, $\mathrm{HA}, \mathrm{OW}, \mathrm{AA}$ and EZD wrote the first draft of the article. All authors reviewed the manuscript for important intellectual content and provided final approval of the version to be published. All authors agreed to be accountable for all aspects of the work in ensuring that questions related to the accuracy or integrity of any part of the work are appropriately investigated and resolved.

Funding The authors have not declared a specific grant for this research from any funding agency in the public, commercial or not-for-profit sectors.

\section{Competing interests None declared.}

Patient consent for publication Not required.

Ethics approval Ethical approval for this study was obtained from the research ethics committees (REC) of the participating universities in Jordan (REC at faculty of pharmacy at Isra University (PH - 2019-07), Saudi Arabia (Prince Norah bint Abdul Rahman University Institutional Review Board (19 - 0038), Kuwait (Health Sciences Centre Ethical Committee at Kuwait University (VDR/EC), Indonesia (REC of Universitas Padjadjaran (04/UN6.KEP/EC/2020), and India (ASPMCH/436/07/2019). Permission and approval for the use of the study questionnaire were acquired from the corresponding author of the original study.

Provenance and peer review Not commissioned; externally peer reviewed. Data availability statement No additional data are available.

Supplemental material This content has been supplied by the author(s). It has not been vetted by BMJ Publishing Group Limited (BMJ) and may not have been peer-reviewed. Any opinions or recommendations discussed are solely those of the author(s) and are not endorsed by BMJ. BMJ disclaims all liability and responsibility arising from any reliance placed on the content. Where the content includes any translated material, BMJ does not warrant the accuracy and reliability of the translations (including but not limited to local regulations, clinical guidelines, terminology, drug names and drug dosages), and is not responsible for any error and/or omissions arising from translation and adaptation or otherwise.

Open access This is an open access article distributed in accordance with the Creative Commons Attribution Non Commercial (CC BY-NC 4.0) license, which permits others to distribute, remix, adapt, build upon this work non-commercially, and license their derivative works on different terms, provided the original work is properly cited, appropriate credit is given, any changes made indicated, and the use is non-commercial. See: http://creativecommons.org/licenses/by-nc/4.0/.

\section{ORCID iDs}

Abdallah Y Naser http://orcid.org/0000-0001-8440-7446

Hassan Alwafi http://orcid.org/0000-0001-5627-1633

Salman Hussain http://orcid.org/0000-0002-1691-8428

\section{REFERENCES}

1 World Health Organization. Patient safety. Education and training 2020, 2020. Available: https://www.who.int/patientsafety/education/ en/

2 Frush KS. Fundamentals of a patient safety program. Pediatr Radiol 2008;38:685-9.

3 Elmontsri M, Almashrafi A, Banarsee R, et al. Status of patient safety culture in Arab countries: a systematic review. BMJ Open 2017;7:e013487.

4 Elmontsri M, Banarsee R, Majeed A. Improving patient safety in developing countries - moving towards an integrated approach. JRSM Open 2018;9:205427041878611.

5 Tregunno D, Ginsburg L, Clarke B, et al. Integrating patient safety into health professionals' curricula: a qualitative study of medical, nursing and pharmacy faculty perspectives. BMJ Qual Saf 2014;23:257-64.

6 Carruthers S, Lawton R, Sandars J, et al. Attitudes to patient safety amongst medical students and tutors: developing a reliable and valid measure. Med Teach 2009;31:e370-6.

7 Hindle D, Braithwaite J, ledema R. The centre for clinical governance research, patient safety research: a review of the technical literature. Sydney: University of New South Wales, 2005.

8 Teigland CL, Blasiak RC, Wilson LA, et al. Patient safety and quality improvement education: a cross-sectional study of medical students preferences and attitudes. BMC Med Educ 2013;13:1-6. 
9 National Patient Safety Foundation. Unmet Needs: Teaching physicians to provide safe patient care [press release]. Boston, MA, 2010.

10 Department of Health. Modernising medical careers. The new curriculum for the foundation years in postgraduate education and training. London: Department of Health, 2007.

11 American Association of Colleges of Nursing. Hallmarks of quality and patient safety: recommended baccalaureate competencies and curricular guidelines to ensure high-quality and safe patient care. $J$ Prof Nurs 2006;22:329-30.

12 Cronenwett L, Sherwood G, Barnsteiner J, et al. Quality and safety education for nurses. Nurs Outlook 2007;55:122-31.

13 Frank J, Brien S. The safety competencies: enhancing patient safety across the health professions. Ottawa, ON: Canadian Patient Safety Institute, 2008.

14 Schumacher D, Slovin S, Riebschleger M, et al. Perspective: beyond counting hours: the importance of supervision, professionalism, transitions of care, and workload in residency training. Acad Med 2012;87:883-8.

15 World Health Organization. The WHO patient safety curriculum guide for medical schools, 2009. Available: https://apps.who.int/iris/handle/ $10665 / 44091$

16 World Health Organization. Multi-professional patient safety curriculum guide. [press release]. WHO Press 2011.

17 Marriott JL, Nation RL, Roller L, et al. Pharmacy education in the context of Australian practice. Am J Pharm Educ 2008;72:131-18.

18 Kiersma ME, Darbishire PL, Plake KS, et al. Laboratory Session to Improve First-year Pharmacy Students' Knowledge and Confidence Concerning the Prevention of Medication Errors. Am J Pharm Educ 2009;73:99-8.

19 Sukkari SR, Sasich LD, Tuttle DA, et al. Development and evaluation of a required patient safety course. Am J Pharm Educ 2008;72:65-10.

20 Lin K, Travlos DV, Wadelin JW, et al. Simulation and introductory pharmacy practice experiences. Am J Pharm Educ 2011;75:209-13.

21 Wilson RM, Michel P, Olsen S, et al. Patient safety in developing countries: retrospective estimation of scale and nature of harm to patients in hospital. BMJ 2012;344:e832.

22 Albsoul AY, Wazaify M, Alkofahi A. Pharmaceutical care education and practice in Jordan in the new millennium. Jordan J Pharm Sci 2008;1:83-90.

23 El Haij M, Hammad A, Afifi H. Pharmacy students' attitudes toward pharmaceutical care in Qatar. Ther Clin Risk Manag 2014;10:121-9.

24 Al-Wazaify M, Matowe L, Albsoul-Younes A, et al. Pharmacy education in Jordan, Saudi Arabia, and Kuwait. Am J Pharm Educ 2006;70:18-4.

25 Basak SC, Sathyanarayana D. Pharmacy education in India. Am J Pharm Educ 2010;74:68-8.

26 Mehmood S, Hasan SMF, Razzakova CM, et al. Abstracts from the 1st JoPPP conference on pharmaceutical policy and practice. $J$ of Pharm Policy and Pract 2020;13.

27 Leotsakos A, Ardolino A, Cheung R, et al. Educating future leaders in patient safety. J Multidiscip Healthc 2014;7:381-8.

28 Bloom SW. The medical school as a social organization: the sources of resistance to change. Med Educ 1989;23:228-41.

29 Nie Y, Li L, Duan Y, et al. Patient safety education for undergraduate medical students: a systematic review. BMC Med Educ 2011;11:33.

30 Wong BM, Etchells EE, Kuper A, et al. Teaching quality improvement and patient safety to trainees: a systematic review. Acad Med 2010;85:1425-39.

31 Kane JM. Patient safety education: overreported and still lacking. Acad Med 2010;85:1397-8.

32 Alper E, Rosenberg El, O'Brien KE, O'Brien K, et al. Patient safety education at U.S. and Canadian medical schools: results from the 2006 clerkship directors in internal medicine survey. Acad Med 2009;84:1672-6.

33 Castel E, Ginsburg L. Patient safety in health professional education: development of a questionnaire to assess student learning. The Canadian patient safety institute, 2008.

34 Candace S. Students' attitudes: the "other" important outcome in statistics education paper presented at: joint statistics meetings. San Francisco, 2003.
35 Ginsburg LR, Tregunno D, Norton PG. Self-reported patient safety competence among new graduates in medicine, nursing and pharmacy. BMJ Qual Saf 2013;22:147-54.

36 Bentler PM, Speckart G. Attitudes "cause" behaviors: a structural equation analysis. J Pers Soc Psychol 1981;40:226-38.

37 Madigosky WS, Headrick LA, Nelson K, et al. Changing and sustaining medical students' knowledge, skills, and attitudes about patient safety and medical Fallibility. Acad Med 2006;81:94-101.

38 Leung G, Patil N. Patient safety in the undergraduate curriculum: medical students' perception. Hong Kong Med J 2010;16:101-5.

39 Halbach JL, Sullivan LL. Teaching medical students about medical errors and patient safety: evaluation of a required curriculum. Academic Medicine 2005;80:600-6.

40 Schnall R, Stone P, Currie L, et al. Development of a self-report instrument to measure patient safety attitudes, skills, and knowledge. J Nurs Scholarsh 2008;40:391-4.

41 Flin R, Patey R, Jackson J, et al. Year 1 medical undergraduates' knowledge of and attitudes to medical error. Med Educ 2009;43:1147-55.

42 Dudas RA, Bundy DG, Miller MR, et al. Can teaching medical students to investigate medication errors change their attitudes towards patient safety? BMJ Qual Saf 2011;20:319-25.

43 Moskowitz E, Veloski JJ, Fields SK, et al. Development and evaluation of a 1-day interclerkship program for medical students on medical errors and patient safety. Am J Med Qual 2007;22:13-17.

44 Kiersma ME, Plake KS, Darbishire PL. Patient safety instruction in US health professions education. Am J Pharm Educ 2011;75:162-12.

45 Walpola RL, Fois RA, Carter SR, et al. Validation of a survey tool to assess the patient safety attitudes of pharmacy students. BMJ Open 2015;5:e008442.

46 World Health Organization. Foodborne disease outbreaks. Guidelines for investigation and control 2017, 2019. Available: http://www.who. int/foodsafety/publications/foodborne disease/Annex 4.pdf

47 Farmer KC. Methods for measuring and monitoring medication regimen adherence in clinical trials and clinical practice. Clin Ther 1999;21:1074-90.

48 MacCallum RC, Widaman KF, Zhang S, et al. Sample size in factor analysis. Psychol Methods 1999;4:84-99.

49 Dornyei Z. Research methods in applied linguistics. New York, 2007.

50 Mathers N, Fox N, Hunn A. Surveys and questionnaires. The NIHR RDS for the East Midlands, 2007.

51 Smith F. Research methods in pharmacy practice. London, 2002.

52 Tegegn HG, Abebe TB, Ayalew MB, et al. Patient safety attitudes of pharmacy students in an Ethiopian university: a cross-sectional study. Drug Healthc Patient Saf 2017;9:19-24.

53 Gilligan AM, Myers J, Nash JD, et al. Educating pharmacy students to improve quality (EPIQ) in colleges and schools of pharmacy. $A m \mathrm{~J}$ Pharm Educ 2012;76:109-7.

54 Bari A, Jabeen U, Bano I, et al. Patient safety awareness among postgraduate students and nurses in a tertiary health care facility. Pak J Med Sci 2017;33:1059-64.

55 Walpola RL, Fois RA, McLachlan AJ, et al. Evaluating the effectiveness of an educational intervention to improve the patient safety attitudes of intern pharmacists. Am J Pharm Educ 2017;81:5-7

56 Nabilou B, Feizi A, Seyedin H. Patient safety in medical education: students' perceptions, knowledge and attitudes. PLoS One 2015; 10:e0135610.

57 Fuji KT, Paschal KA, Galt KA, et al. Pharmacy student attitudes toward an interprofessional patient safety course: an exploratory mixed methods study. Curr Pharm Teach Learn 2010;2:238-47.

58 Sherwood G, Drenkard K. Quality and safety curricula in nursing education: matching practice realities. Nurs Outlook 2007;55:151-5.

59 Shah N, Jawaid M, Shah N, et al. Patient safety: perceptions of medical students of Dow medical College, Karachi. J Pak Med Assoc 2015:65:1261-5.

60 Al-Khaldi Y. Attitude of primary care physicians toward patient safety in Aseer region, Saudi Arabia. J Fam Community Med 2013;20:153-8.

61 Gavaza P, Bui B. Pharmacy students' attitudes toward reporting serious adverse drug events. Am J Pharm Educ 2012;76:194-8. 